\title{
sciendo
}

\author{
EDUARD KRAINIKOV, EUGENIY PROKOPOVYCH, NATALIA TORBYAK
}

\section{Ageism attitudes of Ukrainian students}

\begin{abstract}
Introduction. The article is devoted to the study of factors that determine the students' ageism attitudes, as well as their perception of the image "I am the old".

Aim. To investigate the connection between ageism attitudes with the indicators of conformism and control locus.

Materials and methods. Sample: 100 students of the Faculty of Psychology, Taras Shevchenko National University of Kyiv (specialty "social pedagogy" and "social work"). Toolkit: Leary interpersonal communication skills test, The level of empathy test (I. Yusupov), Big-5 personality questionnaire, The locus of control test (J. Rotter), Questionnaire of ageism attitudes (E. Krainikov).

Results. Younger youths are more conformal and less empathic than older youths. Regarding the openness to the new experience, there were no significant differences between the respondents of both groups. Older youths are characterized by internal control locus comparing to younger youths. In addition, older youths have more positive and objective view to aging and old age. On the contrary, younger youths are more biased towards aging and old age.

Conclusions. The low level of conformism contributes to the formation of positive ageism attitudes, with the relative adoption of the image "I am the old"; the average level of conformism contributes to a balanced approach to aging and old age; a high level of conformism contributes to the formation of a negative ageism attitudes, testifies to the rejection of the image "I am the old". Also, the ageism attitudes are affected by the level of subjective control. The internal control locus correlates with more positive ageism attitudes. Youth associates with a decrease in the level of conformism and increased control of the internal locus; therefore, older youths show more positive ageism attitudes and are likely to adopt the image "I am the old".
\end{abstract}

Keywords: Ageism attitudes, conformism, control locus, youth age.

DOI: $10.2478 /$ pjph-2020-0005

\section{INTRODUCTION}

Old age is perceived by contemporary youths as a bipolar phenomenon: from a positive and a negative point of view [1]. Therefore, on the one hand, older people are perceived as good, balanced, wise, and trustworthy. On the other hand, they are perceived as physically and mentally ill, discreet and depressed [2]. The last view of the final stage of human development, unfortunately, is the most common [3]. Social stereotypes of aging require radical changes. First and foremost, there are the socio-psychological studies of aging issues that can outline the theoretical approaches to this phenomenon, substantiate the methodological grounds for constructing the image of old age, as well as the general attitude to this life stage among representatives of different age groups [4].

Youth is the period of self-determination, the acquisition of psychic, ideological and social maturity, the formation of a worldview, moral consciousness and self-consciousness [5]. This is the time of general stabilization of the person, active selfdevelopment and self-education. However, all this is achieved through extremely strong psycho-emotional experiences frequent mood changes, irritability, anxiety, disappointment with the choice of vocational education, self-doubt, devastation and a sense of loneliness [6]. Such psycho-emotional state of younger youths makes them too sensitive to influence others, causes conformity, the need to follow certain forms of behaviour, assimilation of attitudes and stereotypes, in particular, the ageism [7].

\section{AIM}

The purpose of the article is to investigate the psychological characteristics of the student sample and to compare the level of conformism and the features of the control locus with the ageism attitudes. 


\section{MATERIAL AND METHODS}

On the basis of the theoretical study of the socio-psychological characteristics of youths and the problem of the formation of an adequate image of old age among youths we made the following assumptions:

1. The level of conformism affects the personalities attitudes towards aging and the accompanying changes (a high level of conformism contributes to negative ageism attitudes, which testifies to the rejection of the image "I am the old"; the average level of conformism contributes to balanced ageism attitudes; low level of conformism contributes to positive ageism attitudes, the adoption of the image "I am the old");

2. The level of conformism decreases with age, which causes changes in ageism attitudes (younger youths have a lower level of conformism and, accordingly, more positive ageism attitudes compared with older youths).

The empirical sample consisted of 100 students of the Faculty of Psychology of the Taras Shevchenko National University of Kyiv (specialty "social pedagogy" and "social work"): Group 1-50 students of the $1^{\text {st }}$ year of bachelor studies (age 17-18 years); Group 2-50 students of the $2^{\text {nd }}$ year of master's studies (aged 22-24 years).

The following techniques were used: Leary interpersonal communication skills test, The level of empathy test (I. Yusupov), Big-5 personality questionnaire, The locus of control test (J. Rotter), Questionnaire of ageism attitudes (E. Krainikov).

Leary interpersonal communication skills test is intended for studying the ideas of the subject about himself and the ideal Self, and for studying relationships in small groups. It can determine the prevailing type of attitude to people in self-esteem and mutual evaluation. There are two factors: "domination subordination" and "friendliness - aggressiveness (hostility)". These factors determine the general impression of a person in the processes of interpersonal perception. The orientations or types of attitudes towards others (authoritarian, selfish, aggressive, suspicious, subordinate, dependent, friendly, and altruistic) are distinguished depending on the relevant indicators [8].

The level of empathy test (I. Yusupov) allows to reveal the level of empathy of the subjects. The questionnaire contains six scales that express the attitudes towards parents, animals, the elderly people and children, heroes of tales and media, acquaintances and strangers.

Big-5 personality questionnaire is based on the allocation of five personality factors of temperament and character (neuroticism, extraversion, openness, agreeableness, conscientiousness) [9].

The locus of control test (J. Rotter) diagnoses the localization of control over meaningful events, in other words, the level of personal responsibility. It is based on the distinction between two control locus (internal and external), and, accordingly, two types of people - internals and externals. The internal control locus characterises the people who believe that the occurring events depend primarily on their personal qualities (competence, purposefulness, level of abilities, etc.) and are the logical consequences of their own activities. The external control locus characterises the people who believe that their successes and failures depend primarily on external circumstances - environmental conditions, actions of other people, chance, luck or neglect, etc. [10].
Questionnaire of ageism attitudes (E. Krainikov) can reveal the specificity of the ageism attitudes among young and middle adults. The basis of the Questionnaire is 11 scales: controllability - noncontrollability of aging processes; awareness - suppression of thoughts about the inevitability of own aging; fear - acceptance of physical changes that accompany aging; detachment - proximity to the elderly people; unwillingness - the desire to communicate with the elderly people; conflict - the harmony of relations with the elderly people; hostility benevolence towards the elderly people; unnecessary - utility of the elderly people for the society; positive - negative image of old age; subjective age of the respondent; control questions (intended to reveal the degree of social desirability of the respondent's answers and his attempts to follow social norms).

The study consisted two stages. In the first stage all respondents received forms for each of the five tests. At the second stage we made the calculation of the results: we defined levels of conformism, openness and empathy, the dominant type of control locus, the attitudes towards aging and the physical, psychological and social changes associated with it. At the third stage we analysed the obtained results, the relationships between levels of conformism, openness, empathy, control locus and the ageism attitudes. Also we studied the age characteristics of these connections.

\section{RESULTS}

Leary interpersonal communication skills test (Table 1): 16 respondents $(32 \%)$ in Group 1 and no respondents $(0 \%)$ in Group 2 - high level of conformism (overconsciousness, sacrifice, seeking help and sympathy, obsessive and active with respect to others, the need for social approval, etc.); 21 respondents (42\%) in Group 1 and 12 respondents (24\%) in Group 2 - average level of conformism (shyness, timidity, need for help, tendency to submission, justify authoritative figures, etc.); 13 respondents (26\%) in Group 1 and 38 respondents $(76 \%)$ in Group 2 - low level of conformism (readiness for cooperation, flexibility in problem solving and in conflict situations, sociability, disinterestedness, responsibility, delicacy, empathy, sympathy, caring and caresses, etc.).

TABLE 1. Indicators of conformism level in the investigated groups (by Leary interpersonal communication skills test).

\begin{tabular}{lccc}
\hline \hline \multirow{2}{*}{ Group of respondents } & \multicolumn{3}{c}{ Level of conformism } \\
\cline { 2 - 4 } & low & average & high \\
\hline 1 & $13(26 \%)$ & $21(42 \%)$ & $16(32 \%)$ \\
\hline 2 & $38(76 \%)$ & $12(24 \%)$ & $0(0 \%)$ \\
\hline
\end{tabular}

The level of empathy test (I. Yusupov) (Table 2): 8 respondents (16\%) in Group 1 and 24 respondents (48\%) in Group 2 - high level of empathy (sensitivity to needs and problems of others, sensitivity to feelings and experiences of others, contact, responsiveness, sociability, spirituality, trust in own feelings and intuitions, conflict avoidance, tendency to compromise, etc.); 34 respondents (68\%) in Group 1 and 25 respondents $(50 \%)$ in Group 2 - the optimal level of empathy (tendency to evaluate other people by their actions rather to trust own impressions, understanding own emotions and ability to manifest them, careful communication, restraint of feelings, etc.); 8 respondents (16\%) in Group 1 and 1 respondent $(2 \%)$ in Group 2 -low level of empathy (certain difficulties 
in establishing contacts with people, misunderstanding of others' actions, tendency to precise wording and rational decisions, limited circle of close friends, etc.).

TABLE 2. Indicators of the level of empathy in the studied groups (by The level of empathy test).

\begin{tabular}{lccc}
\hline \hline \multirow{2}{*}{ Group of respondents } & \multicolumn{3}{c}{ Empathy level } \\
\cline { 2 - 4 } & low & optimal & high \\
\hline 1 & $8(16 \%)$ & $34(68 \%)$ & $8(16 \%)$ \\
\hline 2 & $1(2 \%)$ & $25(50 \%)$ & $24(48 \%)$ \\
\hline
\end{tabular}

Big-5 personality questionnaire (Table 3): 43 respondents (86\%) in Group 1 and 32 respondents (64\%) in Group 2 - low indicators of openness (excessive practicality, realism, rationality, material values' beliefs, purposefulness, the advantage of stability and reliability); 5 respondents (10\%) in Group 1 and 14 respondents (28\%) in Group 2 - average indicators of openness; 2 respondents (4\%) in Group 1 and 4 respondents (8\%) in Group 2 - high indicators of openness (expressiveness, emotionality, frivolity, aesthetics, artistry, attention to own feelings and intuition, versatility of interests, avoidance of routine).

TABLE 3. Indicators of openness in the investigated groups (by Big-5 personality questionnaire).

\begin{tabular}{lccc}
\hline \hline \multirow{2}{*}{ Group of respondents } & \multicolumn{3}{c}{ Openness } \\
\cline { 2 - 4 } & low & average & high \\
\hline 1 & $43(86 \%)$ & $5(10 \%)$ & $2(4 \%)$ \\
\hline 2 & $32(64 \%)$ & $14(28 \%)$ & $4(8 \%)$ \\
\hline
\end{tabular}

The locus of control test (J. Rotter) (Table 4): 3 respondents $(6 \%)$ in Group 1 and 22 respondents (44\%) in Group 2 - internal control locus (believe that occurring events depend on their personal qualities such as competence, purposefulness and abilities, are the logical result of own activities; seek independence and personal strength, make maximum efforts to achieve their goals and implement planned plans); 26 respondents (52\%) in Group 1 and 22 respondents (44\%) in Group 2 - unclear control locus; 21 respondents (42\%) in Group 1 and 6 respondents (12\%) in Group 2 - external control locus (inclination to consider own successes or failures as a result of external forces, luck, chance, pressure of others, etc.; rejection of own role in events of their life, passivity, lack of desire achieving their goals).

TABLE 4. Indicators of locus of control in the studied groups (by The locus of control test).

\begin{tabular}{lccc}
\hline \hline \multirow{2}{*}{ Group of respondents } & \multicolumn{3}{c}{ Locus control } \\
\cline { 2 - 4 } & internal & unclearly & external \\
\hline 1 & $3(6 \%)$ & $26(52 \%)$ & $21(42 \%)$ \\
\hline 2 & $22(44 \%)$ & $22(44 \%)$ & $6(12 \%)$ \\
\hline
\end{tabular}

Questionnaire of aging attitudes (E. Krainikov) (Table 5): 16 respondents $(32 \%)$ in Group 1 and no respondents $(0 \%)$ in Group 2 - negative ageism attitudes (hostility, prejudice, anxiety, insecurity in relations with older people); 28 respondents $(56 \%)$ in Group 1 and 19 respondents (38\%) in Group 2 - adequate ageism attitudes (balance of ideas about controllability and lack of control over aging processes, fear of physical changes and adoption of them, positive and negative images of old age, ability to communicate with elderly people, to show goodness to them); 6 respondents (12\%) in Group 1 and 31 respondents $(62 \%)$ in Group 2 -positive ageism attitudes (protectionist attitudes towards the elderly people, harmony of relations with them, respect for elderly people and admiration for their wisdom).

TABLE 5. Indicators of ageism attitudes in the studied groups (by Questionnaire on attitudes towards aging).

\begin{tabular}{lccc}
\hline \hline \multirow{2}{*}{ Group of respondents } & \multicolumn{3}{c}{ Attitudes towards Aging } \\
\cline { 2 - 4 } & negative & adequate & positive \\
\hline 1 & $16(32 \%)$ & $28(56 \%)$ & $6(12 \%)$ \\
\hline 2 & $0(0 \%)$ & $19(38 \%)$ & $31(62 \%)$ \\
\hline
\end{tabular}

\section{DISCUSSION}

The results showed that younger youths are more conformal and less empathic than older youths. Regarding the openness to new experience, there were no significant differences between the respondents of both groups. With age, there is a change in control locus - from the external to the internal. In addition, older youths are more positively and objectively related to aging and old age. On the contrary, younger youths are more biased towards aging and old age.

To test the assumption about the relationship between the level of conformism and the ageism attitudes, we have carried out a correlation analysis of the data. As a result, it was found that the correlation coefficient between the level of conformism and the ageism attitudes among respondents in Group 1 is 0.786 . This indicates a rather strong connection between these factors, high statistical significance (the probability of errors is less than 1\%) and the inverse orientation (an increase of the index of one factor is accompanied by a decrease of the index of the other - the higher level of conformism, the more negative general attitude towards aging).

Concerning additional factors (openness, control locus, level of empathy), we did not reveal statistically significant relationships between them and the ageism attitudes. There were the following correlation coefficients: between the openness and the general attitude towards aging - 0.094 (the connection is very weak, direct, the probability of error is $51 \%$ ); between the control locus and the general attitude towards aging -0.363 (the connection is moderate, inverse relationship, error probability $-1 \%$ ); between the level of empathy and the general attitude towards aging -0.445 (the connection is moderate, direct, probability of error - less than 1\%) (Table 6).

TABLE 6. Correlation analysis of data of Group 1 respondents.

\begin{tabular}{|c|c|c|c|c|c|}
\hline No. & Relationship & $\begin{array}{c}\text { Correlation } \\
\text { coefficient }\end{array}$ & $\begin{array}{c}\text { Correlation } \\
\text { direction }\end{array}$ & $\begin{array}{c}\text { Correlation } \\
\text { strength }\end{array}$ & Significance \\
\hline 1. & $\begin{array}{c}\text { Level of } \\
\text { conformism - } \\
\text { General attitude } \\
\text { towards aging }\end{array}$ & -0.786 & reverse & strong & 0.000 \\
\hline 2. & $\begin{array}{c}\text { Openness - } \\
\text { General attitude } \\
\text { towards aging }\end{array}$ & 0.094 & direct & very weak & 0.517 \\
\hline 3. & $\begin{array}{l}\text { Control locus - } \\
\text { General attitude } \\
\text { towards aging }\end{array}$ & -0.363 & reverse & moderate & 0.010 \\
\hline 4. & $\begin{array}{c}\text { The level of em- } \\
\text { pathy - General } \\
\text { attitude towards } \\
\text { aging }\end{array}$ & 0.445 & direct & moderate & 0.001 \\
\hline
\end{tabular}


In respondents of Group 2, the correlation coefficient between the level of conformism and the general attitude towards aging is 0.522 . This indicates a significant relationship between these factors, high statistical significance (probability of error $-1 \%$ ) and inverse orientation (an increase of the index of one factor is accompanied by a decrease of the index of the other - the higher level of conformism among younger youths, the more negative their general attitude towards aging).

Concerning additional factors (openness, control locus, level of empathy), statistically significant relationships between them and the ageism attitudes were not revealed. There were the following correlation coefficients: between the openness and the general attitude towards aging -0.106 (the connection is weak, direct, probability of error $-60 \%$ ); between the level of empathy and the general attitude towards aging -0.364 (the connection is moderate, direct, probability of error $10 \%$ ). The only exception was the subjective control factor: its relationship with the general attitude towards aging and old age is statistically significant, rather strong, direct (correlation coefficient - 0.501) (Table 7).

TABLE 7. Correlation analysis of data of Group 2 respondents.

\begin{tabular}{|c|c|c|c|c|c|}
\hline No. & Relationship & $\begin{array}{c}\text { Correlation } \\
\text { coefficient }\end{array}$ & $\begin{array}{c}\text { Correlation } \\
\text { direction }\end{array}$ & $\begin{array}{c}\text { Correlation } \\
\text { strength }\end{array}$ & Significance \\
\hline 1. & $\begin{array}{c}\text { Level of } \\
\text { conformism - } \\
\text { General attitude } \\
\text { towards aging }\end{array}$ & -0.522 & reverse & significant & 0.001 \\
\hline 2. & $\begin{array}{c}\text { Openness - } \\
\text { General attitude } \\
\text { towards aging }\end{array}$ & 0.106 & direct & weak & 0.601 \\
\hline 3. & $\begin{array}{l}\text { Control locus - } \\
\text { General attitude } \\
\text { towards aging }\end{array}$ & -0.501 & reverse & significant & 0.000 \\
\hline 4. & $\begin{array}{c}\text { The level of em- } \\
\text { pathy - General } \\
\text { attitude towards } \\
\text { aging }\end{array}$ & 0.364 & direct & moderate & 0.010 \\
\hline
\end{tabular}

\section{CONCLUSIONS}

The ageism attitudes are affected by the level of conformism [11]. The low level of conformism contributes to positive ageism attitudes, with the relative adoption of the image "I am the old"; the average level of conformism contributes to balanced attitudes toward aging and old age; a high level of conformism contributes to negative ageism attitudes, testifies to the rejection of the image "I am the old". Also, the ageism attitudes are affected by the level of subjective control. The internal control locus correlates with more positive ageism attitudes. Youth is associated with a decrease of the level of conformism, and internal control locus; therefore, older youths show more positive ageism attitudes and adoption of the image "I am the old". Such changes may be due to the peculiarities of socialization that occurs during studying the specialty "social pedagogy" and "social work", which involves the acquisition of personal maturity and adoption of the more tolerant outlook [12].

\section{REFERENCES}

1. Krainikov E. Gerontology: Dictionary-directory. Kyiv: Palyvoda Publisher; 2010. p.352.

2. Nelson TD. Psychology of prejudice (2nd ed). United Kingdom: Pearson; 2005. p. 336.

3. Krainikov E. Old Age: The age of compensation against the age of deficit. Bulletin of the Taras Shevchenko National University of Kyiv. Series: Psychology. 2014;1(1): 45-9.

4. Krainikov, E. Gerontopsychology: Handbook. Kyiv: Publishing of Taras Shevchenko National University of Kyiv; 2018. p. 231

5. Craig GJ, Baucum D. Human Development (9th ed). United Kingdom: Pearson; 2001. p. 736.

6. Newcombe N. Child development: Change over time (8th ed). United Kingdom: Harpercollins College Div; 1995. p. 585.

7. Berk LE. Child development (9th ed). United Kingdom: Pearson; 2013.

8. The Great Encyclopaedia of Psychological tests (contributing author A. Karelin). Moscow: Exmo; 2006. p. 416.

9. Pervin LA, John OP. Personality: Theory and research (9th ed). New York: John Wiley \& Sons; 2004. p.640.

10. Anastasi A, Urbina,S. Psychological Testing (7th ed). United Kingdom: Pearson; 1997. p.736.

11. Ageev V. Intergroup Interaction. Moscow: Publishing of Moscow University; 1990. p. 240 .

12. Shibutani T. Society and personality: An interactionist approach to social psychology. New Jersey:Transaction Publisher; 1991. p. 648

\section{Corresponding author}

Eduard Krainikov

Department of Developmental Psychology, Faculty of Psychology,

Taras Shevchenko National University of Kyiv,

E-mail: psy_edw@ukr.net 